\title{
A formación do profesorado de lingua galega: perspectivas pedagóxicas e modelo lingüístico
}

\author{
Galician Language Training of teachers: didactic perspectives and language model
}

\author{
Estefanía Mosquera Castro \\ Universidade da Coruña
}

\begin{abstract}
Resumo
Este traballo analizará desde unha perspectiva teórico-práctica as necesidades formativas do profesorado de lingua galega na Educación Primaria como resultado da particular situación sociolingüística en que se encontra a lingua galega. A nosa análise verifica problemas a nivel pedagóxico que provocan no alumnado de grao unha falta de motivación pola súa aprendizaxe, un modelo de lingua precario e unhas aptitudes lingüísticas negativas, que condicionarán o posterior proceso de ensino-aprendizaxe en que figurarán como docentes e, tamén, como referentes. A discusión formulará as medidas necesarias para garantir unha competencia lingüística mínima neste idioma que capacite para a posterior práctica docente.
\end{abstract}

Palabras clave: actitudes lingüísticas, competencia comunicativa, lingua galega, educación, formación

\begin{abstract}
This work analyses from a theoretical and practical perspective Galician language training needs of teachers in Primary Education, taking into account the particular sociolinguistic situation in which Galician language is. Our review will verify teaching problems that cause in Galician language students a lack of motivation for learning, a poor precarious language model and a negative linguistic aptitude, that will determine the subsequent process of teaching and learning, where nowadays students will be the teachers and, therefore, the linguistic referents. The discussion will aim the necessary measures to ensure a minimum proficiency in this language that qualifies for the later teaching.
\end{abstract}

Keywords: language attitudes, communicative competence, Galician language, Education, training

Nos últimos anos a cuestión lingüística constitúe na Galiza un dos eixos centrais do debate político, especialmente no que respecta ao seu funcionamento no sistema educativo galego. Hai cinco anos as tensións estaban provocadas pola derrogación do Decreto 124/2007 e a aprobación do Decreto 79/2010, pois pasabamos dun marco lexislativo que fixaba un mínimo do $50 \%$ das materias en galego a un modelo educativo en que "se poñen topes ao seu uso, onde non se garante como idioma vehicular nin tan sequera para quen o solicite expresamente, [e] onde se prohibe que determinadas materias se poidan impartir en galego [...] como se for posíbel o plurilingüismo negando a propia” lingua” (Callón, 2011).
Resulta preocupante que a lingua constiúa un problema a nivel político, pois seguindo Freixeiro Mato (2009), xulgamos que o futuro dunha lingua minorizada como é a galega está indisolubelmente ligada á política, dado que "só esta, por activa ou por pasiva, pode facer que supere a situación de minoración, que fique nela ou mesmo que desapareza”. Pois ben, o uso, en moitos casos, interesado e partidista da lingua como tema de debate quebrou o consenso político e normalizador que existira até ese momento na Galiza e deu paso a un contexto en que o idioma virou un motivo de discordias e disputas. Esta situación acabou por xerar na conciencia dos galegos e das galegas a percepción da lingua -a minoritaria- como problema, mesmo para a sobrevivencia da lingua dominante, como así se deduce do preámbulo do Decreto 79/2010 en que se alude á necesidade de fixar tamén mínimos para o español, pois non facelo podería mudar o modelo de conxunción de linguas desenvolvido en Galicia.

Como indica Callón (2011), este Decreto foi contestado de forma unánime por numerosas entidades: organizacións e asociacións. Igualmente, foi rexeitado polo Consello Escolar de Galiza e informado de modo desfavorábel polo Consello Consultivo, ao tempo que se levaron a cabo diversos procesos xudiciais contra el. Con todo, estes contenciosos non conseguiron a súa derogación e cinco anos despois da súa aprobación, este decreto permanece aínda vixente e continúa a ser albo de numerosas críticas, na medida en que formula un modelo educativo regresivo que pon en perigo non só a pervivencia da lingua, mais tamén a adquisición dunha mínima competencia en galego por parte das xeracións máis novas. Xeracións entre as que se encontran aquelas que se constituirán como futuros docentes e referentes lingüísticos para as que estiveren aínda por chegar.

As reprobacións recibidas por este Decreto poden ser resumidas, en liñas xerais, nos seguintes termos: en primeiro lugar, non parte da realidade sociolingüística da Galiza, en que existen dúas linguas que non se encontran na mesma situación. Así, non se discrimina positivamente o galego -en tanto que lingua minorizadafronte o español e o tratamento que se lle outorga é formalmente o mesmo e xera, por tanto, un tratamento materialmente desigual .

Desglosado por etapas educativas, cómpre sinalarmos que na Educación Infantil o decreto non regula nin permite aos centros deseñaren as accións pedagóxicas necesarias para conseguiren que o estudantado domine as dúas linguas oficiais, só a maioritaria. Ademais esta é 
determinada por unha consulta ás familias, a cal pode estar condicionada por prexuízos lingüísticos en detrimento, máis unha vez, da lingua minorizada (Iglesias Álvarez, 2012). Na Educación Primaria o número de horas impartidas en galego diminúe, o alumnado ten plena liberdade no referente á utilización das linguas e os proxectos de innovación permiten que se impartan en inglés as materias en galego que determina o Decreto, o que provoca que nalgúns casos o contacto co galego se restrinxa únicamente á materia de lingua, especialmente en ámbitos urbanos. Por último, na Educación Secundaria, o número de materias impartidas en galego é inferior ás que se asignan para o español, de modo que se mantén a redución horaria sinalada tamén para Primaria que, ademais é unha repartición polémica, dado que fai desaparecer o galego do ámbito científico-tecnolóxico, o que afecta negativamente á súa consideración social.

Recentemente, os resultados da enquisa realizada polo Instituto Galego de Estatística (IGE) sobre o coñecemento e uso do galego evidenciaron o fracaso das políticas normalizadoras ao constataren unha perda continuada e constante de galegofalantes, que xa non constitúe a lingua maioritaria da sociedade galega, como apuntaba Freixeiro Mato (2009). Na actualidade, só o $31 \%$ da populación galega fala sempre en galego e, ademais, estes usos remiten principalmente para as faixas etarias de maior idade. Así, o 75\% dos menores de 15 anos recoñecen que falan sempre ou case sempre español, ao tempo que o $22,7 \%$ afirma que sabe falar pouco ou nada en galego. E esta realidade afecta directamente ao ensino e á situación do galego nel, onde a porcentaxe de estudantado que recibe aulas en galego é do $2,15 \%$, moi lonxe do $15 \%$ constatado en 2008 , cando aínda estaba vixente o Decreto 124/2007. Ao tempo, a porcentaxe para o español aumentou nestes últimos anos até superar o $51 \%$.

O sistema educativo constitúe unha peza clave para garantir o futuro do galego, mais a involución evidente dos últimos anos constata o seu fracaso, pois en moitos casos incidiu no abandono do galego por parte de moitas crianzas e, ademais, "non garantiu nin tan sequera que o alumnado puidese finalizar o ensino obrigatorio cunha competencia comunicativa en galego igual á conseguida en castelán” (Callón, 2011). A nosa experiencia como docentes de lingua galega no grao en Educación Primaria verifica esta situación, isto é, un nivel certamente baixo e nalgúns casos nulo de competencia en lingua galega, non só no alumnado que inicia os seus estudos, mais en moitos casos tamén naquel que os finaliza e que na teoría está capacitado para exercer a docencia neste -e tamén deste- idioma. Así, encontrámonos con estudantado que non chega ao ensino universitario coas competencias lingüísticas que se lle presupoñen, o que implica un dilema relevante para o docente da didáctica en lingua galega: de que modo nos podemos centrar no como cando non se sabe o que?

O obxectivo deste traballo será determinar cales son as variábeis que, para alén do alén do marco social e político xa analizado, condicionan esta situación e deseñar, en consecuencia, diversas hipótesis de actuación para a reverter.

\section{Método}

Os resultados desta investigación derivan da análise teórica de fontes de investigación previas, na maioría dos casos con base en datos cuantitativos, como os proporcionados polo Instituto Galego de Estatística e da observación e da análise crítica dos coñecementos , das habilidades e dos xuízos de valor dunha mostra formada por 140 alumnos e alumnas da materia de Lingua galega e a súa didáctica correspondente ao primeiro curso do grao de Educación Primaria.

A recollida de datos levouse a cabo durante o curso 2014/2015, dado que se trataba dunha materia de primeiro cuatrimestre, de modo que os resultados son certamente actuais, o que permite que sexan contrastados cos que achega sobre estas cuestións o IGE, publicados en decembro de 2014 e relativos a 2013. Neste sentido, tamén facilitarán a extracción de relacións máis ou menos evidentes de causa-efecto e a formulación de posíbeis solucións.

\section{Resultados}

\section{O modelo de lingua}

A realidade pluricultural e, sobre todo, plurilingüe do Estado español obriga a asumirmos unha serie de premisas na didáctica da(s) lingua(s) diferentes ás que se priorizan nos estados monolingües. Así, será necesario termos en consideración que, por exemplo, existen comunidades en que conviven dúas ou máis linguas, unha delas normalmente en situación de inferioridade, caso do galego na Galiza. Neste contexto, o marco sociolingüístico de cada unha delas determinará distintas prácticas docentes. Así, no que respecta á lingua galega parece necesario atendermos á formación lingüística do profesorado, especialmente nos niveis que non exixen especialización filolóxica, como o dos graos en Educación Infantil e Primaria.

Hai xa máis de dúas décadas Cassany , Luna e Sanz (1994) advertían que existía unha parte importante do profesorado que, inclusive sendo nativo noutra lingua autonómica, presentaba unha maior facilidade de expresión, tanto oral como escrita, en español ou que, cando menos, manifestaba unha competencia lingüística sensibelmente inferior á que cumpriría. Pois ben, vinte anos despois, esta situación é aínda máis evidente, precisamente polos retrocesos en materia educativa xa sinalados. Así, o actual decreto tamén produciu importantes reducións no que respecta á necesidade de o profesorado demostrar o coñecemento da lingua minorizada e propia da Galiza, na medida en que as probas que garantían a competencia en lingua galega deixaron de ser eliminatorias no acceso ao funcionariado, de modo que é posíbel que as nosas crianzas reciban ensino en galego ou -máis preocupante aínda- de galego por parte de persoas que non dominan o idioma.

Neste sentido, e como reflicten tamén en certo modo os resultados do IGE, parte da poboación galega profesores, avogados, fontaneiros, tendeiros etc.pronuncia mal e ten unha lingua chea de calcos lexicais e interferencias da lingua dominante, neste caso do español. E aínda que sexa tamén un problema a nivel social, esta situación é especialmente preocupante cando 
é o corpo docente quen non coñece a lingua galega, polas súas implicacións a nivel educativo, que poderían formularse da seguinte maneira: de que modo pode unha persoa con este perfil vehicular e, sobre todo, estimular a expresión nesa lingua? E, por outra parte, constitúe o modelo de lingua que se transmite desde o sistema educativo un referente lingüístico auténtico?

Para Cassany, Luna e Sanz (1994), o profesorado é consciente desta problemática e iso prodúcelle moita inseguridade. Para a minimizar, é frecuente que se escude na norma, dado que esta é explícita e controlábel, mais sen encarar o ensino-aprendizaxe da lingua como instrumento de comunicación. Porén a situación sociolingüística particular da lingua galega impediu e impide aínda en moitos casos que a norma sexa o muro desde o que acometer esta batalla: o proceso de estandarización deste idioma é, se comparado cos da súa contorna, aínda moi recente, de modo que é tamén outro foco de inseguridades e de prexuízos (Iglesias Álvarez, 2012) que se reforzan polas aínda constantes controversias -moitas veces públicas- entre os partidarios das distintas solucións ortográficas.

Neste contexto, para moitas persoas o emprego do galego -sexa o modelo que for-parece de por si meritorio e non consideran necesario que se exixa un grao de corrección lingüística minimamente aceptábel. Por tanto, o que para outras linguas -as normalizadas- como o español sería inadmisíbel é entendido aquí como algo natural, máis próximo á lingua "que fala o pobo labrego e mariñeiro, verdadeiro posuídor e transmisor do idioma" (Freixeiro Mato, 2002). Sen ir máis lonxe, na materia de "Lingua galega e a súa didáctica" mostrei ao alumnado dous modelos de lingua oral a través do monólogo, un claramente interferido e no que a propia deturpación era motivo de mofa e outro, igualmente gracioso, libre de interferencias e calcos do español. Pois aínda que a grande maioría valorizou positivamente este último, houbo persoas que o consideraban artificioso e que preferían o primeiro por se tratar dunha lingua máis próxima á que fala a xente, como se as circunstancias históricas e sociais non fosen suficientes para explicar o porqué desta situación e as súas implicacións no futuro da lingua . Así mesmo, o modelo de lingua presente nos traballos do alumnado de grao reflicte tamén un alto grao de deturpación.

No entanto, concordamos con Freixeiro Mato (2009) cando sinala que "hoxe xa non debería ser suficiente con que as persoas que se dedican á docencia [...] , e que teñen un compromiso claramente asumido co idioma propio, se expresen en galego de calquera maneira”. E, do mesmo modo, xa non pode ser xustificábel a proxección pública dunha lingua deturpada e castrapizada "por parte de quen ten a preparación e a capacidade suficiente como para o poder falar con corrección, a pouco que se esforzar”. Os estudos sobre o galego avanzaron moito nas últimas décadas, de igual modo que o proceso de fixación dun modelo de lingua máis auténtico. Na actualidade contamos con ferramentas suficientes para determos o proceso de degradación interna da lingua e superarmos o desleixo e a despreocupación con que ás veces é tratada. Mais para o lograrmos é necesario o esforzo e o coidado de todos, e especialmente daquelas persoas con máis capacidade de influencia social, caso do corpo docente.

Máis as cuestións relativas aos modelos de lingua non se limitan únicamente ao que se considera correcto ou incorrecto, mais sobre todo deberían ser expresadas en termos de adecuación e inadecuación. Así, entendemos que é necesario incidir na ilexitimidade daquilo que non é galego e tratarmos de eliminar estas prácticas da nosa praxe diaria (Sanmartín Rei, 2009), máis tamén cómpre sermos conscientes de que dentro do galego existen diferentes modelos ou rexistros lingüísticos e que todos eles son perfectamente válidos en cadanseu contexto. Sobre este particular, asumimos as palabras de Bechara (2000), quen deseña unha boa maridaxe entre estas dúas perspectivas ao defender que a escola non debe "ficar no dogmatismo de uma gramática intransigente nem tampouco no populismo onde tudo se aceita” e, neste sentido, considera necesario "uma integração dessas duas atitudes em benefício não só da educação lingüística do aluno, mas também da sua adequada preparação para as ocasiões em que ele precise bater á porta da sociedade”.

Para o caso concreto da lingua galega, achamos que existen dous focos a que prestar especial atención desde unha perspectiva didáctica. Por unha banda, ao tratamento dos fenómenos dialectais e, por outra, á distancia entre os modelos de lingua oral e escrita, que se ben é evidente nin sempre se reflicte desde unha óptica pedagóxica, especialmente no referente ás linguas non normalizadas en que, como xa apuntamos, os docentes adoitan fundamentarse de modo case exclusivo nas normas gráficas, tamén no que respecta á lingua oral e a todos os seus rexistros. A respecto da diversidade dialectal, Sánchez Rei (2011) considera que a escola debe garantir, non só a interiorización da variedade estandarizada, mais tamén o mantemento das modalidades dialectais nas ocasións en que se consideraren oportunas.

Así, os docentes, sexa cal for o nivel educativo en que desenvolveren a súa labor e a materia que ensinaren, deberían ter un bo dominio da variedade dialectal da zona en que exercer, así como unhas nocións xerais da distribución xeográfica dos fenómenos máis importantes. E, igualmente, deberán ser conscientes de que as estratexias pedagóxicas para o ensino-aprendizaxe da lingua variarán se o noso alumnado é maioritariamente galegofalante ou españolfalante (Fernández Rei 1987), así como varían coa idade. Non termos en consideración estas premisas pode provocar unha percepción distorsionada da variedade dialectal galega en que se magnifica a distancia real -certamente pequena- entre a norma e as variedades locais.

E unha visión igualmente negativa a respecto do estándar da lingua galega pode ser tamén asumida se obviarmos as diferenzas que separan as formas da oralidade e as da escrita, asumindo os ditames presentes na normativa para todas elas. De acordó con Regueira (2013), a variedade oral manifesta unha menor fixación do que a escrita e "nunca está codificada de maneira explícita como unha 'normativa' que hai que seguir de maneira necesaria”, mais con frecuencia o modelo de lingua oral parte da variedade falada polas elites sociais. A falta de referentes lingüísticos noutros medios concede 
un papel fundamental á escola e moi especialmente aos docentes de lingua galega. E, neste sentido, eludirmos esta realidade e aplicarmos pautas de corrección da escrita á lingua oral orixinará producións lingüísticas ríxidas e afastadas da coloquialidade que, en moitas ocasións, rexe esta variedade .

Así, consideramos, na liña do sinalado por Cassany, Luna e Sanz (1994), que a escola debe ser un espazo que ofreza a elasticidade necesaria para o alumnado ser capaz de se expresar amplamente nos distintos rexistros lingüísticos, orais e escritos, e de se dirixir a persoas diferentes segundo for a situación comunicativa. E, na nosa opinión isto só se conseguirá coñecendo o amplo abano de posibilidades que lle outorga a diversidade lingüística do galego e eliminando as posíbeis interferencias presentes no seu modelo de lingua. É deste modo que debemos orientar, na nosa opinión, a formación dos futuros docentes, especialmente o dos niveis iniciais, pois serán eles os primeiros referentes e os encargados de estimularen o amor pola lingua.

\section{Os enfoques metodolóxicos}

Mais os problemas relativos á adquisición dunha competencia mínimamente aceptábel na lingua galega non rematan aquí. Nesta liña, xulgamos que a formación pedagóxica que recibe o profesorado a respecto do noso idioma tamén manifesta certas lagoas, sobre todo no referente ás metodoloxías que deben ser utilizadas na aprendizaxe de linguas, e máis concretamente de linguas minorizadas, e tamén no tocante ás expectativas ou aos obxectivos que se queren obter deste proceso. Trátase na realidade de dúas pezas do mesmo puzzle e, por tanto, se unha non está na orientación apropiada, a outra tampouco encaixará.

A primeira delas ten que ver co emprego de metodoloxías tradicionais e gramaticalistas, pouco enfocadas no uso e na funcionalidade das linguas que, aínda non sendo o enfoque ideal, é aínda con diferenza o que se adoita seguir para o ensino-aprendizaxe das linguas maternas ou da Lingua 1 (L1). Nestes casos a escola e máis concretamente a materia de lingua é a encargada de lle ofrecer ás crianzas os coñecementos linguiísticos de carácter xeral e os procedementos propios de organización dese sistema de signos (regras gramaticais, léxico etc.). De acordo con Cassany (1999), esta metodoloxía concibe a lingua obxecto de estudo como unha realidade homoxénea, con frecuencia representada exclusivamente na norma estándar -e por tanto, na modalidade escrita- e todo desde unha óptica prescritiva. Esta perspectiva, claramente reducionista, continúa sendo aínda frecuente na aprendizaxe de L1 precisamente porque a perspectiva comunicativa e funcional vén dada polo resto do contorno que rodea o alumno, tamén o escolar, mais fundamentalmente o familiar e o mediático.

De feito, as crianzas xa inician a súa etapa educativa cunha relativa competencia expresiva nesa L1 e, nalgúns casos, é probábel que tamén saiban expresarse ou cando menos coñezan de forma pasiva algunha outra lingua -0 que se denomina segunda lingua ou L2-, ben por motivos familiares ou simplemente porque no territorio en que reside coexistan dúas ou máis linguas.. Neste sentido, vira evidente que a metodoloxía empregada no ensino-aprendizaxe dunha e doutra lingua non pode ser idéntica, pois no caso da L2 "los aprendizajes lingüísticos de carácter general ya han sido incorporados $\mathrm{y}$, por lo tanto, la tarea se reduce a funciones de aplicación y de contextualización” (Cassany, Luna e Sanz, 1994).

A situación lingüística do Estado español obriga a facermos certas matizacións a respecto do que se considera como L2, pois non podemos equiparar linguas estranxeiras como o francés, o alemán ou o inglés ao catalán, o euskera ou o galego, idiomas minorizados, mais que aínda así teñen certa presenza nas súas respectivas comunidades. Así, haberá contextos en que a asociación entre L1 e L2 non sexa respectivamente español e galego, mais á inversa, o que implicará as necesarias adaptacións pedagóxicas (Fernández Rei, 1987). Porén, os datos proporcionados polo IGE sitúan o galego cada vez máis na posición de L2, dado que xa non é a lingua maioritaria da sociedade, especialmente nos ambientes citadinos, e nalgúns casos a materia de Lingua Galega é, como xa apuntamos, practicamente o único contexto en que o alumnado está en contacto co idioma. Esta situación obriga os docentes a mudar ou cando menor priorizar outros enfoques que, para alén de contidos gramaticais, poñan a énfase nos usos. Seguindo o formulado por Ares e Arias (1986), as aulas de lingua galega non deben ser, en ningún momento, unha clase exclusiva en que se aprende gramática e normas, mais ao contrario non podemos esquecer a práctica continuada do idioma, a través da súa expresión escrita, mais fundamentalmente oral.

Nesta liña e a teor da situación lingüística actual da sociedade galega, consideramos que o obxectivo que debe primar no ensino-aprendizaxe do noso idioma, sobre todo nos niveis iniciais que é onde exerce o noso alumnado de grao, non debe ser a formación de gramáticos en potencia, mais fundamentalmente de falantes, aínda a sermos conscientes de que o coñecemento da gramática é tamén básico para esta finalidade . Eis a segunda pezza do puzzle. Será unha vez dado este paso en que deberemos prestar atención á introdución das correccións necesarias para obter unha lingua máis dúcitl e de calidade

E aínda que estes problemas metodolóxicos afectan en moitos casos tamén ao ensino de linguas estranxeiras léase inglés- no ámbito educativo español, en que o alumnado con frecuencia dedica anos á aprendizaxe das regras gramaticais da L2, mais no final da súa formación raramente é capaz de as utilizar para se comunicar nela, a condición particular do galego en tanto que segunda lingua presenta certas vantaxes que deben ser aproveitadas no seu beneficio. Así, o carácter non nativo do profesorado de inglés xustifica en parte que o ensino da L2 sexa realizado con maior cautela, dado que a improvisación pode aumentar o risco de cometer erros. Neste sentido, as actividades dos materiais didácticos do profesorado, con frecuencia coas solucións, ofrecen unha zona de confort, ausente nas metodoloxías comunicativas (Cortés Moreno, 2005).

Ao contrario, a competencia lingüística dos docentes de lingua galega, teñan ou non como lingua inicial este 
idioma, é ou cando menos debería ser a dunha persoa nativa, motivo porque non resulta tan complexo centrar o ensino-aprendizaxe no uso real da lingua en situacións de comunicación auténtica. Será, de feito, a súa condición de nativo a que lle permitirá nalgúns casos contrariar certas regras gramaticais e manter a credibilidade. Desde esta óptica, o alumnado deixaría de aprender a lingua exclusivamente a través de actividades mecánicas e descontextualizadas, orientadas cara ás regras da variedade normativa e, en consecuencia, contribuiría para un maior coñecemento da lingua como instrumento de interacción, ao tempo que refutaría prexuízos tan afianzados na sociedade como "o galego é difícil” ou de que "non se fala o galego correcto", entre outros (Iglesias Álvarez, 2012).

A formación académica do profesorado non debe ser allea a esta realidade e debe proporcionar aos futuros docentes as ferramentas metodolóxicas e didácticas necesarias para a superar e para avanzar na mellora das competencias lingüísticas dos galegos e das galegas desde as primeiras etapas educativas. En todo o caso, convén sermos conscientes de que se trata dunha carreira a contrareloxo polas limitacións derivadas da mala ou da escasa planificación dos estudos para estes corpos docentes. En concreto, á lingua galega e a súa didáctica dedícanselle no grao de Educación Primaria 12 créditos nos catro anos de formación.

\section{Discusión}

A análise realizada nas páxinas precedentes permitiu verificarmos a delicada situación por que atravesa o galego a nivel sociolingüístico e mais concretamente no contexto educativo. Así, a lexislación educativa vixente en materia lingüística non garante unha discriminación positiva do galego fronte ao español que permita que o alumnado finalice a súa etapa formativa cunha competencia similar nas dúas linguas. A esta situación, cómpre sumarmos os problemas a nivel pedagóxico, debido á limitada renovación metodolóxica que afecta ao ensino desta lingua, e á escasa presenza de docentes cun modelo de lingua aceptábel que actúe como referente da aprendizaxe lingüística. Trátase de diferentes partes dunha mesma realidade que, ademais se retroalimenta, cando ese alumnado con escaso dominio lingüístico é o encargado de exercer no futuro como docente, con independencia da materia que imparta, mais especialmente o de lingua galega.

Ao non termos a autoridade suficiente para mudarmos os condicionamentos adversos que de iure nos son impostos, xulgamos que a formación que se imparte no grao debe centrar a atención nos dous elementos tratados na presente contribución para poder transformar de facto a realidade lingüística que nos rodea. En concreto, consideramos necesario unha aproximación funcionalista e comunicativa como a que ten lugar no ensino-aprendizaxe de linguas estranxeiras ou de segundas linguas, e igualmente un modelo lingüístico de calidade, liberado de interferencias gramaticais máis tamén psicolóxicas, que garantan o seu futuro. $\mathrm{Na}$ actualidade é complexo acadarmos en tan pouco espazo de tempo estes obxectivos, posto que alén do como -a didáctica- aínda é necesario atendermos ao que -a lingua. Porén, será preciso realizarmos ese esforzo para que os docentes que formamos consigan frear o círculo vicioso a que nos referimos.

Neste sentido, o seu labor debe ser o de servir como referente e o de axudar de forma activa o alumnado para que este poida adquirir un modelo de lingua auténtico, de calidade e con prestixio. A este respecto, non serve só con eliminar as posíbeis interferencias do español, mais tamén convén que os docentes actúen de modo responsábel e consecuente tanto no relativo ás actitudes lingüísticas como no referente á diversidade intralinguística que se lles mostra nas aulas. Por esta razón, a norma deberá ser máis un modelo lingüístico -en ningún caso o único-, á par doutros como o das variedades dialectais, as contextuais ou o dos rexistros máis informais e coloquiais, pois será este o único modo de ampliar a competencia lingüística do alumnado e de o dotar das ferramentas comunicativas necesarias para se integrar con éxito na sociedade. Consideramos que só así conseguiremos, nun futuro, abordar a didáctica do galego coa normalidade que continuamente se lle está a negar.

\section{Referencias}

Ares Vázquez, C. e Arias Méndez, X. (1986). "O galego estándar sen merma da variante dialectal". Revista Galega de Educación, núm. 3, pp. 29-31.

Bechara, E. (2000): “A correçao idiomática e o conceito de exemplaridade”, pp.11-18. En Azeredo, J.C. (org.). Língua Portuguesa em Debate. Conhecimento e Ensino. Petrópolis: Vozes.

Callón, C. (2011). Como defenderes os teus dereitos lingüísticos. Vigo: Xerais.

Cassany, D. (1999). "Los enfoques comunicativos: elogio y critica”. Lingüística y literatura, núm. 36-37, pp. 11-33.

Cassany, D., Luna, M. e Sanz, G. (1994). Enseñar lengua. Barcelona: Graó.

Cortés Moreno, M. (2005). “¿Hay que enseñar gramática a los estudiantes de una lengua extranjera?”. Cauce. Revista Internacional de Filología y su didáctica, núm. 28, pp. 89-108.

Fernández Rei, F. (1987). “Aplicación da dialectoloxía na aprendizaxe do galego común". Grial, núm. 96, pp. 131-150.

Freixeiro Mato, X. R. (2002). Lingua galega: normalidade e conflito. Santiago de Compostela: Laiovento.

Freixeiro Mato, X. R. (2009). Lingua de calidade. Vigo: Xerais.

Iglesias Álvarez, A. (2012). “Actitudes e prexuízos lingüísticos en Galicia. A súa influencia nos usos”. A letra miúda. Revista de Sociolingüística, núm. 1.

Regueira, X. L. (2013). "Estándar oral e modelos de lingua”. A letra miúda. Revista de Sociolingüística, núm. 2.

Sánchez Rei, X. M. (2011). Lingua galega e variación dialectal. Noia: Laiovento.

Sanmartín Rei, G. (2009). Nos camiños do entusiasmo. Calidade da lingua e planificación. Vigo: Xerais. 